\title{
Translational Control in Stem Cells
}

\author{
Soroush Tahmasebi ${ }^{1 *}$, Mehdi Amiri',3 and Nahum Sonenberg ${ }^{2,3 *}$ \\ ${ }^{1}$ Department of Pharmacology, University of Illinois at Chicago, Chicago, IL, United States, ${ }^{2}$ Goodman Cancer Research \\ Center, McGill University, Montreal, QC, Canada, ${ }^{3}$ Department of Biochemistry, McGill University, Montreal, QC, Canada
}

Simultaneous measurements of mRNA and protein abundance and turnover in mammalian cells, have revealed that a significant portion of the cellular proteome is controlled by mRNA translation. Recent studies have demonstrated that both embryonic and somatic stem cells are dependent on low translation rates to maintain an undifferentiated state. Conversely, differentiation requires increased protein synthesis and failure to do so prevents differentiation. Notably, the low translation in stem cell populations is independent of the cell cycle, indicating that stem cells use unique strategies to decouple these fundamental cellular processes. In this chapter, we discuss different mechanisms used by stem cells to control translation, as well as the developmental consequences of translational deregulation.

OPEN ACCESS

Edited by:

Akio Kanai,

Keio University, Japan

Reviewed by:

Thomas Preiss,

Australian National University,

Australia

Toshinobu Fujiwara,

Kindai University, Japan

*Correspondence:

Soroush Tahmasebi

sorousht@uic.edu

Nahum Sonenberg

nahum.sonenberg@mcgill.ca

Specialty section:

This article was submitted to

$R N A$,

a section of the journal

Frontiers in Genetics

Received: 19 September 2018

Accepted: 17 December 2018

Published: 15 January 2019

Citation:

Tahmasebi S, Amiri M and Sonenberg N (2019) Translational

Control in Stem Cells.

Front. Genet. 9:709.

doi: 10.3389/fgene.2018.00709
Keywords: translational control, stem cell, protein synthesis, development, mRNA

\section{INTRODUCTION}

\section{The Importance of Translation Control in Mammalian Cells and Stem Cells}

The abundance of proteins in a mammalian cell varies by several orders of magnitude $\left(10^{3}\right.$ $10^{8}$ molecules per cell) (Li et al., 2014; Li and Biggin, 2015). Transcription rate, messenger RNA (mRNA) turnover, translation rate, and protein degradation are four fundamental cellular processes that regulate protein abundance. The poor correlation between protein and mRNA abundance, which is documented in numerous studies, and higher conservation of protein expression compared to mRNA expression across species suggest that post-transcriptional control explains a large percentage of protein variability (Gygi et al., 1999; Maier et al., 2009; Vogel et al., 2010; Schwanhausser et al., 2011; Aviner et al., 2013; Khan et al., 2013; Sharma et al., 2015). Parallel measurements of mRNA and protein levels along with mRNA and protein turnover demonstrated that the translation rate plays a dominant role in regulating the cellular proteome (Schwanhausser et al., 2011). Others reported a much higher correlation between mRNA and protein levels $\left(R^{2} \cong 0.6-0.9\right)$ (Li et al., 2014; Jovanovic et al., 2015). Nevertheless, these studies suggest that cell status dictates the contribution of transcriptional versus translational control in defining the proteome of the cell. During steady state or after long-term differentiation/adaptation, transcriptional control is considered the main determinant of the cellular proteome, whereas during early stages of state transition (differentiation/adaptation), translational control plays a dominant role (Lu et al., 2009; Ingolia et al., 2011; Kristensen et al., 2013). Translational control allows cells to quickly respond to internal and external stimuli before a new transcription program comes into effect (Liu et al., 2016).

Notably, among different proteins in the cells the levels of transcription factors and proteins performing essential cellular processes (e.g., ribosomal and mitochondrial proteins), are more stringently subjected to translational control (Lee et al., 2013; Jovanovic et al., 2015). This exquisite 
dependency on translational control, also referred to as "translation on demand," has been well documented during early developmental stages, a period when transcription is known to be silenced. For instance, selective translational upregulation of few transcription factors (e.g., Nanog, Sox19b, and Pou5f1) is essential for activation of zygotic genome and maternalto-zygotic transition (MZT) in zebrafish (Lee et al., 2013). The regulatory information encrypted in the $5^{\prime}$ and $3^{\prime}$ mRNA untranslated regions' (UTRs) sequences plays a critical role in rendering a subset of mRNAs sensitive to translational control (Hinnebusch et al., 2016). Ribosome footprinting analysis underscored the importance of the upstream open reading frame (uORF) in translational control of several key pluripotency factors, such as Myc and Nanog (Ingolia et al., 2011). In addition to the importance of translational control in defining the cellular proteome, translational control also impacts transcription. A recent study uncovered a delicate fine-tuning between translation and transcription in embryonic stem cells (ESCs) and peri-implantation embryos. An acute inhibition of global translation (using cycloheximide or mTOR inhibitors) disrupts the hypertranscription and euchromatic state of ESCs (Bulut-Karslioglu et al., 2018). This finding highlights the importance of coordination between transcription and translation for maintenance of self-renewal and pluripotency.

\section{Initiation, the Rate Limiting Step of Translation}

mRNA translation is divided into four steps; initiation, elongation, termination, and ribosome recycling. Initiation is the process through which the small subunit of the ribosome (40S), as a component of the $43 \mathrm{~S}$ preinitiation complex, is recruited to the mRNA, and scans the mRNA $5^{\prime}$ UTR from $5^{\prime}$ to $3^{\prime}$ to recognize the start codon. Following recognition, the $80 \mathrm{~S}$ initiation complex is assembled at the start codon and elongation will proceed (Sonenberg and Hinnebusch, 2009; Hinnebusch et al., 2016).

Eukaryotic ribosomes (consisting of 4 ribosomal RNAs and 80 ribosomal proteins) are not fully equipped to directly bind to mRNAs and hence, start translation. The activities of multiple eukaryotic translation initiation factors (eIFs) are therefore required for recruitment of ribosomes to mRNAs and translation initiation. The orchestrated activity of eIFs culminates in the assembly of two multisubunit complexes, the $43 \mathrm{~S}$ preinitiation complex (consist of small ribosomal subunit, initiator tRNA, and eIF1, 1A, 2, and 3) and the eIF4F complex (consist of eIF4E, eIF4A, and eIF4G) at $5^{\prime}$ end of mRNA. In eukaryotic cells, the abundance of a key component of the eIF4F complex, cap-binding protein eukaryotic translation initiation factor $4 \mathrm{E}$ (eIF4E), is far less than that of ribosomes $\left[41 \times 10^{4}\right.$ molecules of eIF4E compared to $1064 \times 10^{4}$ cytosolic ribosomes per HeLa cell (Merrick and Pavitt, 2018)], which makes eIF4E availability the limiting factor for translation initiation. The activity of eIF2B has been also identified as a rate-limiting step in translation initiation. The eIF2B is a guanine nucleotideexchange factor (GEF) that converts eIF2.GDP to eIF2.GTP, a critical step requires for the formation of the $43 \mathrm{~S}$ preinitiation complex. Consequently, most mammalian cells, including stem cells, have a surplus of non-translating ribosomes, which could be engaged in translation through the control of the activity of eIFs. Several signaling pathways such as the mechanistic Target of Rapamycin (mTOR), the mitogen activated protein kinase (MAPK), and the integrated stress response (ISR) control translation through phosphorylation of activators (e.g., eIF4E and eIF $2 \alpha$ ) or inhibitors [e.g., 4E-BPs (eIF4E-binding proteins; inhibitors of eIF4E), PDCD4 (Programmed Cell Death 4; an inhibitor of eIF4A)] of translation initiation. This provides a tunable translation regulatory system that adjusts the translation rate, according to cellular demands.

\section{GLOBAL TRANSLATION IS INHIBITED IN STEM CELL POPULATIONS}

Studies in both embryonic and adult stem cells demonstrated that stem cells require low translation rates to maintain an undifferentiated status (Figure 1; Sampath et al., 2008; Signer et al., 2014; Blanco et al., 2016; Zismanov et al., 2016). Sampath et al. (2008) first found that global translation is low in undifferentiated ESCs compared to EB (embryoid body). Differentiation [5 days culture in the absence of LIF (leukemia inhibitory factor)] increases polysome density in the differentiating cells by $\sim 60 \%$ and $\left[{ }^{35} \mathrm{~S}\right]$ methionine incorporation by $\sim 2$-fold as compared to undifferentiated ESCs. The increase in translation of differentiated cells coincides with a significant increase in the content of total RNA $(\sim 50 \%)$, ribosomal RNA ( $\sim 20 \%$ ), and proteins ( $\sim 30 \%)$.

Similar to ESCs, global translation is suppressed in somatic stem cells. Studies on various tissue specific stem cells such as hematopoietic stem cells (HSCs), hair follicle stem cells (HFSCs), and muscle stem cells (satellite cells) demonstrated that protein synthesis is restricted in stem cell population and is increased upon differentiation (Signer et al., 2014; Blanco et al., 2016; Zismanov et al., 2016).

Tight control of translation is crucial for the maintenance of HSCs, as only a $30 \%$ decrease (using $R p l 24^{B s t} /+$ mice, where ribosome protein Rpl24 is partially depleted) or increase (using Mx1-Cre; Pten ${ }^{f l / f l}$ mice, where Pten is depleted from adult hematopoietic cells) in protein synthesis is sufficient to impair the proliferation and self-renewal of HSCs (Signer et al., 2014). The rate of protein synthesis also impacts normal hair cycle through regulation of the self-renewal and differentiation of HFSCs (Blanco et al., 2016). Activation of HFSCs during hair growth (transition from telogen to anagen) coincides with a profound increase in protein synthesis (Figure 1D). Committed progenitor cells located at the inner root sheath (IRS) display the highest translation rate compared to other progenitors. The importance of translation control in regulating HFSC has been highlighted in NOP2/Sun RNA Methyltransferase Family Member 2 (NSUN2) knockout (KO) mouse (Blanco et al., 2016). NSUN2 is an RNA methyltransferase that converts cytosine to 5-methylcytosine (m5C), and is required for decoding activity and stability of tRNAs. Hypomethylated tRNAs that are accumulated in NSUN2 $\mathrm{KO}$ cells, are cleaved by endonuclease and the resulting tRNA 


\section{* Translation Rate: Low High}

A

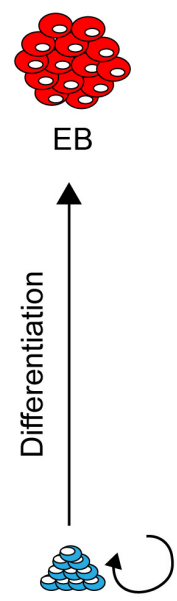

ESC
B
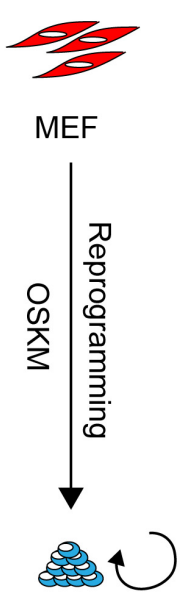

iPSC
C
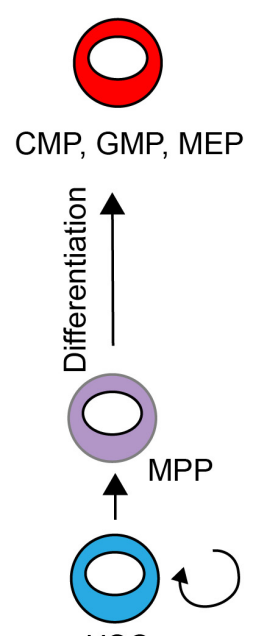

HSC
D

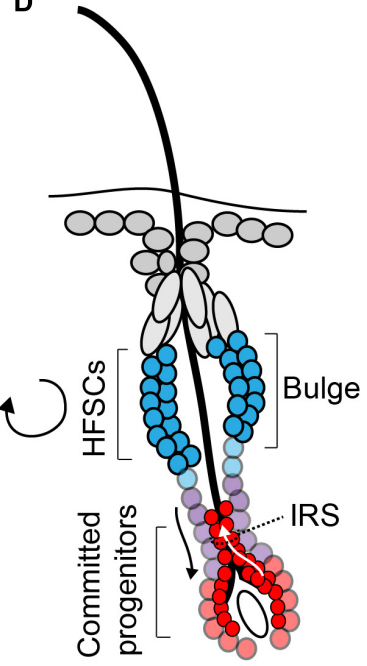

$\mathbf{E}$
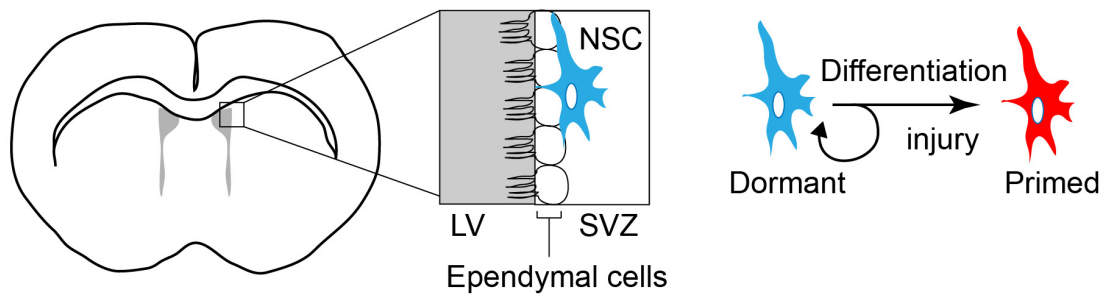

F
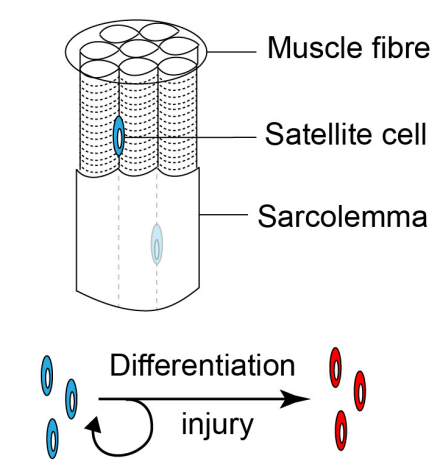

quiescence

Activated

G

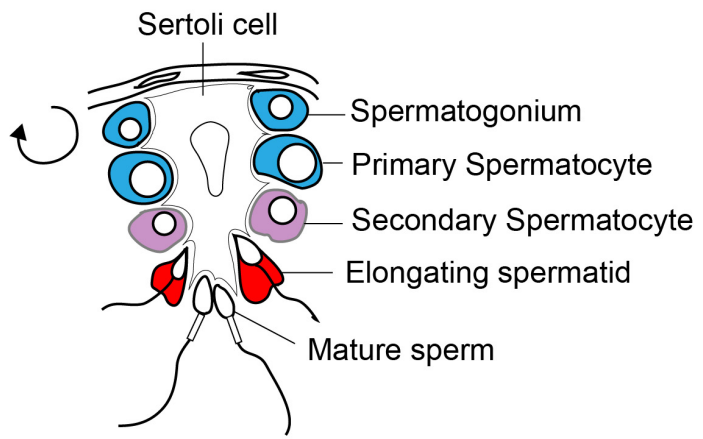

FIGURE 1 | Translation inhibition is a hallmark of stem cells. The rate of protein synthesis in pluripotent ESCs (A) or iPSCs (B) and in multipotent adult stem cells (C-G) is lower compared to early differentiating cells or progenitors. Blue and red color defines low and high translation rates, respectively.

fragments inhibit translation initiation (Spriggs et al., 2010; Ivanov et al., 2011; Sobala and Hutvagner, 2013). NSUN2 is highly expressed in committed progenitor cells of the epidermis. The inhibition of translation in NSUN2 KO cells blocks the differentiation of epidermal stem cells toward committed progenitors, which leads to cyclic alopecia in the mouse (Blanco et al., 2016).
Lack of Pseudouridylate Synthase 7 (PUS7) has the opposite effect to that of NSUN2 deficiency. PUS7 is a member of pseudouridine synthases (PUSs) that catalyzes the pseudouridylation $(\Psi)$ of a subset of tRNAs at U8 (uridine at position 8 of tRNA). Pseudouridylation of a group of tRNAderived small fragments inhibit translation initiation, and consequently, the absence of PUS7 promotes global translation. 
Interestingly, a recent study uncovered the importance of PUS7 activity in maintenance and differentiation of ESCs and HSCs (Guzzi et al., 2018).

Translational control also plays a central role in differentiation of adult stem cells in the testis. This has been well documented in several translationally defective mouse models including in NSUN2 KO mouse. In addition to the epidermis, NSUN2 is highly expressed in testis and plays a critical role in germ cell differentiation. Consequently, NSUN2 KO males not only have defect in hair growth but they also display infertility. During the late stages of spermatogenesis, translation activation of germ cell-specific mRNAs is required for successful generation of spermatozoa (Figure 1G). Inhibition of global translation due to NSUN2 depletion halts the progression of a germ cell through the late stages of spermatogenesis, engendering infertility. Interestingly, a similar phenotype (male infertility and defect in late spermatogenesis) has also been reported in Paip2a $\{$ Pabp [poly(A)-binding protein]-interacting protein 2A\} KO mice, where global translation is inhibited (Yanagiya et al., 2010). Three Pabp - interacting proteins (Paips) have been discovered in mammals [Paip1 (Craig et al., 1998), Paip2a (Khaleghpour et al., 2001), and Paip2b (Berlanga et al., 2006)]. This family of proteins regulates mRNA translation and stability through the control of PABP function. Lack of PAIP2s has been linked to translation activation as their bindings to PABP compete with the interaction of PABP with the poly(A) tail and eIF4G (Khaleghpour et al., 2001; Karim et al., 2006). During late spermatogenesis, translational derepression of a subset of mRNAs, such as Prms (protamines) and Tps (transition proteins), is essential for the generation of functional spermatozoa. This translational derepression coincides with shortening of poly(A) tails, from approximately 180 nucleotides in a translationally repressed state to 30 nucleotides in a translationally active state (Kleene, 1989). Conversely, lack of PAIPs during spermatogenesis inhibits translation of Prms and Tps. This effect has been explained by an excess expression of Pabpc1 (an isoform of Pabp that is expressed in Elongating spermatids) (Yanagiya et al., 2010). Altogether, these findings demonstrate that translational control is a key modulator of stem cell differentiation.

\section{HOW DO STEM CELLS MAINTAIN A LOW TRANSLATION RATE?}

\section{Ribosome Biogenesis}

Under physiological condition, ribosome abundance is not considered a limiting factor for translation initiation in stem cells (Figure 2). However, studies in Drosophila and mammals suggest that differentiation of stem cells relies on increased ribosomal biogenesis (Ingolia et al., 2011; Zhang et al., 2014; Sanchez et al., 2016). Sampath et al. (2008) found that ribosomal RNAs are $\sim 20 \%$ elevated in 5 day EB as compared to mESCs. Using ribosome footprinting, Ingolia et al. (2011) identified a modest increase in translation of ribosomal proteins (RPs) mRNAs at early stages of differentiation ( $36 \mathrm{~h}$ after LIF withdrawal), whereas translation of RPs strongly suppressed at later time points (8 days EBs). They concluded that the increase in expression of RPs at early stages of differentiation is required for the profound increase in global translation observed at later stages and is mediated by mTORC1 activation.

Single cell sequencing of neural stem cells (NSCs) demonstrated that in response to injury, there is a dramatic increase in transcription of the genes involved in ribosome biogenesis (Llorens-Bobadilla et al., 2015). The increase in ribosome biogenesis triggers a global increase in protein synthesis, which is required for the activation and differentiation of NSCs. Study of ribosomophaties also highlights the importance of the ribosome in differentiation. Ribosomopathies are a group of inherited human diseases that are caused by mutations in the small or large ribosomal subunits or factors involved in ribosome biogenesis (Tahmasebi et al., 2018a). While ribosomes can be found in almost all mammalian cells, it is surprising that defects in ribosomal function preferably affect only specific cell types, most prominently erythroid progenitors. Several hypotheses have been proposed to explain the cell type and tissue specificity associated with ribosomopathies. One model suggests that ribosomes are heterogeneous and each cell type possesses its own unique set of ribosomes, which are specialized in translating cell type-specific mRNAs (specialized ribosome model) (Xue and Barna, 2012; Shi et al., 2017). An alternative model suggests that ribosomes are homogenous, but different mRNAs or cell types have different sensitivity to ribosomal defects (ribosome concentration model) (Mills and Green, 2017). For instance, studies in Diamond-Blackfan anemia (DBA) demonstrated that mutations in $60 \mathrm{~S}$ or $40 \mathrm{~S}$ ribosomal proteins [such as RPL5, RPL11, RPS7, RPS10 among others (Tahmasebi et al., 2018a)] decrease the ribosome levels but leave the composition of the ribosomes intact. This renders ribosome availability a limiting factor for translation of a subset of mRNAs, such as GATA1, that play a critical role in differentiation of HSCs (Khajuria et al., 2018). In support of this model, mutation of other factors that impair ribosome biogenesis have been linked to depletion of HSCs (Le Bouteiller et al., 2013).

\section{mTORC1/4E-BPs}

The importance of the mTORC1/4E-BPs pathway in self-renewal and differentiation of stem cells is well documented in ESCs, HSCs, and NSCs (Sampath et al., 2008; Hartman et al., 2013; Signer et al., 2014, 2016; Tahmasebi et al., 2016). ESCs have the remarkable ability to maintain low mTORC1 activity in the presence of LIF (an activator of the PI3K-Akt pathway) and a high content of amino acids and serum (15\% FBS) in the medium (Sampath et al., 2008; Tahmasebi et al., 2014, 2016). Combining polysome profiling with microarray analysis, Sampath et al. (2008) discovered a hierarchical translation control network downstream of the mTORC1/4E-BP pathway that regulates expression of pro-differentiation mRNAs. mTOR activity and phosphorylation of 4E-BP1 increase in response to ESC differentiation. The importance of $4 \mathrm{E}-\mathrm{BPs}$ in the regulation of self-renewal and differentiation of ESCs has been also examined in ESCs lacking 4E-BP1 and 2 (the two 4E$\mathrm{BP}$ isoforms that are highly expressed in ESCs). 4E-BP1/2 DKO ESCs proliferate slower than WT cells and are prone to differentiation partly through increased translation of $Y Y 2$ 


\section{Undifferentiated stem cell}

\section{Differentiated \\ progenitor cell}

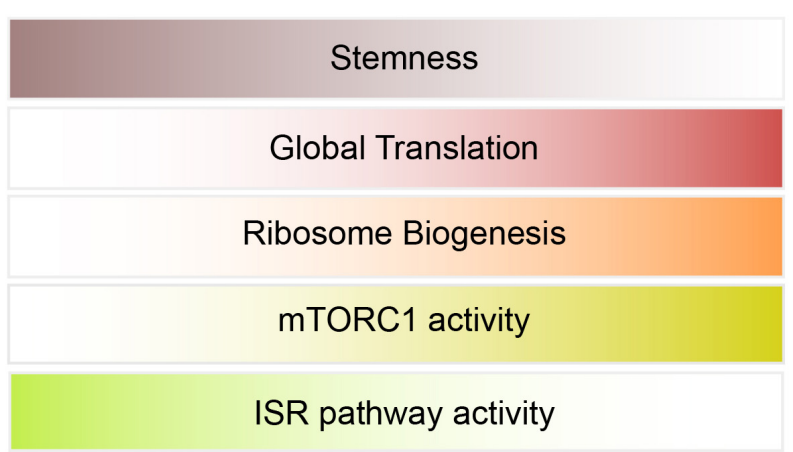

FIGURE 2 | Underlying mechanisms of translation inhibition in stem cells.

mRNA (Tahmasebi et al., 2016). In addition, the mTORC1/4EBP pathway plays a critical role in the generation of induced pluripotent stem cells (iPSCs) (Chen et al., 2011; He et al., 2012; Tahmasebi et al., 2014). Interestingly, more recent evidence indicates that ESCs are largely tolerant to mTOR inhibition. Inhibition of the mTOR pathway by mTOR inhibitors (INK128 and RapaLink-1) engenders a reversible paused state in ESCs and blastocysts. Paused ESCs are translationally and transcriptionally silent, but remain pluripotent, mimicking a diapause state of blastocysts in vivo (Bulut-Karslioglu et al., 2016).

There is increasing evidence that the mTOR/4E-BP pathway also contributes to translation inhibition and maintenance of adult stem cells such as HSCs and NSCs. Phosphorylation of $4 \mathrm{E}-\mathrm{BP} 1$ is reduced in HSC/MPPs (multipotent progenitors) compared to most progenitor cells, and abrogation of $4 \mathrm{E}-$ BP1 and 2 specifically increases protein synthesis in HSCs, while having a negative effect on their ability for reconstitution (Signer et al., 2016). The subventricular zone (SVZ) in the fetal and adult brain of mammals harbors a small population of cells with stem cell properties (self-renewal and multipotency), known as NSCs (Figure 1E; Gage, 2000). Hartman et al. (2013) demonstrated that the mTORC1 is suppressed in quiescent NSCs located at the SVZ. The activity of mTORC1 is increased (judged by phosphorylation of $4 \mathrm{E}-\mathrm{BP} 1 / 2$ and ribosomal protein S6) in proliferating NSC progenitors undergoing differentiation. Genetic (shRNA against Rheb or Raptor) or pharmacological (rapamycin) inhibition of mTORC1 blocks differentiation of NSCs to intermediate progenitors, resulting in lower neuron production. Hyperactivation of mTORC1 mediated by a constitutively active Rheb (Rheb ${ }^{\mathrm{CA}}$ ) induces differentiation of NSC and reduces the population of self-renewing NSCs, specifically through inhibition of 4E-BPs (Hartman et al., 2013).

\section{ISR Pathway}

Recent studies highlighted the importance of the ISR pathway in translational control of stem cells. The ISR pathway activation is triggered by a family of four kinases that control translation initiation through phosphorylation of eIF $2 \alpha$. The eIF2 $\alpha$ kinases encompass HRI (heme-regulated inhibitor; also known as eIF2AK1), PKR (protein kinase RNA-activated; also known as eIF2AK2), PERK [PKR-like endoplasmic reticulum (ER) kinase; also known as eIF2AK3], and GCN2 (general control nonderepressible 2; also known as eIF2AK4). All four kinases share a conserved kinase domain but each has evolved unique regulatory domains that only sense and respond to a distinct set of stressors. While p-eIF $2 \alpha$ decreases global translation, it has a stimulatory effect on the translation of selective mRNAs containing uORFs within their $5^{\prime}$ UTR such as Atf4, Chop, and BiP. By suppressing global translation but increasing translation of stress-induced mRNAs, cells can overcome the stress condition. The significance of HRI and PERK in erythropoiesis and differentiation of pancreatic beta cells, respectively, has been uncovered using transgenic animal models (Han et al., 2001; Harding et al., 2001; Zhang et al., 2006). The discovery of PERK mutations in Wolcott-Rallison syndrome (WRS), a multi-systemic disease with early-onset diabetes mellitus, further supports the findings in animal models (Delepine et al., 2000). Additionally, genome-wide translational profiling underscores the importance of eIF2 phosphorylation in erythroid homeostasis (Paolini et al., 2018). Increasing evidence in recent years emerged that demonstrate the importance of the ISR pathway in stem cells. Zismanov et al. (2016) used the eIF $2 \alpha^{\mathrm{S} 51 \mathrm{~A} / \mathrm{S} 51 \mathrm{~A}}$ mouse model (where phosphorylation of eIF2 $\alpha$ has been blocked by mutation of serine 51 to alanine) to highlight the significance of eIF $2 \alpha$ phosphorylation in muscle stem cells. Muscle stem cells, also known as satellite cells, are a small population of cells located between sarcolemma and the basal lamina of muscle fibers (Figure 1F), and play a critical role in growth and regeneration of muscles. In quiescent satellite cells, the level of p-eIF2 $\alpha$ is high but it quickly decreases once the cells differentiate and start to activate the myogenic program. The high level of p-eIF2 $\alpha$ in the quiescent satellite cells has been linked to relatively high activity of PERK in these cells. Zismanov et al. (2016) further showed that in addition to the well-characterized p-eIF2 $\alpha$ targets (e.g., Atf4 and Chop), translation of numerous stem cell-related mRNAs such as the deubiquitinating enzyme Usp9x (Ivanova et al., 2002; Ramalho-Santos et al., 2002) relies on p-eIF2 $\alpha$. Importantly, a chemical-mediated increase in p-eIF2 $\alpha$ 
TABLE 1 | Lethal phenotypes resulting from change in activity or lack of elFs in mouse.

\begin{tabular}{|c|c|c|}
\hline Gene & Lethal phenotype & Reference \\
\hline Eif2b3 & $\begin{array}{l}\text { Preweaning or embryonic lethality, complete penetrance, decreased hemoglobin } \\
\text { content }\end{array}$ & Meehan et al., 2017 \\
\hline Eif2b4 & Preweaning lethality, complete penetrance, enlarged heart & Meehan et al., 2017 \\
\hline elF2alpha $551 \mathrm{~A}$ & Neonatal lethality, complete penetrance, neonates died within $18 \mathrm{~h}$ after birth & Scheuner et al., 2001 \\
\hline Ppp1r15b & Preweaning lethality, all die in the first day of postnatal life & Harding et al., 2009 \\
\hline Ppp1r15a; Ppp1r15b & Embryonic lethal, Embryo die before preimplantation period & Harding et al., 2009 \\
\hline Eif4e & Embryonic lethal, Embryo die before E6.5 & Truitt et al., 2015 \\
\hline Eif4e2 & Perinatal lethality & Morita et al., 2012 \\
\hline Nat1/Eif4G2 & Embryonic lethal, defects in gastrulation & Yamanaka et al., 2000 \\
\hline elF3m & Embryonic lethal at the peri-implantation stage & Zeng et al., 2013 \\
\hline elF3e & Embryonic lethal, Embryo die before E10.5 & Sadato et al., 2018 \\
\hline Dhx29 & Preweaning lethality, complete penetrance & International Mouse Phenotyping Consortium (IMPC) \\
\hline
\end{tabular}

(using sal003, a compound that inhibits the eIF2 $\alpha$ phosphatase Gadd34/PP1) promotes self-renewal and regenerative capacity of cultured satellite cells, indicating that modulation of $\mathrm{p}$-eIF $2 \alpha$ can be used as a strategy to improve stem cell transplantation. The mTORC1 pathway also regulates the activity of satellite cells and is required for their transition from G0 quiescent state into $G_{\text {Alert }}$ phase (an "alerting" state of quiescent stem cells that allows them to immediately enter the cell cycle and respond to injury or stress) (Rodgers et al., 2014). Thus, in addition to p-eIF2 $\alpha$, it is highly likely that the activity of 4E-BPs contributes to translation inhibition in satellite cells.

Studies in other stem cell populations also uncovered the importance of p-eIF $2 \alpha$ in self-renewal and differentiation. Undifferentiated ESCs have a high level of p-eIF2 $\alpha$, while differentiation decreases p-eIF2 $\alpha$ levels (Friend et al., 2015). p-eIF $2 \alpha$ promotes translation of stem cell factors, such as Nanog and $M y c$ containing uORFs in their 5'UTR. A study in human HSCs demonstrated that PERK and PERK-dependent genes (Atf4, Chop, and Gadd34) are enriched in HSPCs (HSCs and progenitor cells; $\mathrm{CD} 34^{+} \mathrm{CD} 38^{-}$) as compared to more differentiated progenitors $\left(\mathrm{CD} 34^{+} \mathrm{CD} 38^{+}\right.$) (van Galen et al., 2014). Accordingly, HSCs display a higher sensitivity (increased apoptosis and reduced clonogenic capacity) to ER stress compared to progenitors. Overexpression of ERDJ4 (a member of the J protein family that fosters protein folding in ER) in HSCs decreases ER stress and promotes in vivo transplantation (van Galen et al., 2014).

\section{Other Translation Factors}

It is very likely that additional translational factors or regulators contribute to translational control in stem cells. For instance, recent data support the importance of $\mathrm{m}(6) \mathrm{A}$ RNA modification in differentiation of ESCs (Batista et al., 2014). Despite the long list of biochemically characterized eIFs, only few studies examined the role of eIFs in stem cells. Lack of eIFs in mouse is often embryonic or perinatal lethal and has detrimental effects on stem cells and normal development (Table 1).

\section{DAP5/p97/NAT1, elF4G2}

Nat1 (also known as DAP5 and eIF4G2) is an eIF4G homolog that interacts with eIF4A, eIF3, and MNK. However, in contrast to eIF4G, p97/DAP5/Nat1 does not bind to eIF4E and therefore has been proposed to be involved in capindependent translation (Henis-Korenblit et al., 2002; Liberman et al., 2015). Nat1 KO mice are embryonic lethal and display defects in the gastrulation step (Yamanaka et al., 2000). Proliferation and global translation are similar between Nat1 null ESCs and their WT counterpart. However, Nat1 null cells are resistant to differentiation in both mouse and human (Yamanaka et al., 2000; Yoffe et al., 2016). Ribosome foot-printing analysis of Nat1 KO ESCs demonstrated that lack of Nat1 causes a decrease translation of differentiationpromoting factors such as Map3k3 and Sos1 (Sugiyama et al., 2017).

\section{TRANSLATION INHIBITION IN STEM CELLS IS CELL CYCLE INDEPENDENT}

Studies on embryonic and adult stem cells demonstrated that translation inhibition is independent of replication rate in these cells. Mouse ESCs exhibit a fast replication rate (divide every $8-10 \mathrm{~h}$ as compared to $>16 \mathrm{~h}$ of differentiated cells), and have a unique cell cycle control (Singh and Dalton, 2009), as they progress through a very short G1 phase (15\%), while residing mostly in S phase (65\%). Human ESCs maintain similar cell cycle structure as mouse ESCs, however, they replicate much slower (divide every 30-38 h) (Singh and Dalton, 2009). Adult stem cells are slow-growing cells that spend most of their time in a dormant state (G0/G1) and only divide in response to physiological or pathological stimuli. Low translation rate of HSCs is not just a consequence of their dormant state, as when protein synthesis was compared using cell cycle-matched populations (S/G2/M or G0/G1), HSCs exhibited a lower translation rate compared to differentiated progenitors (Signer et al., 2014). Study in HFSCs also demonstrates that the rate of protein synthesis is independent of cell cycle and proliferation (Blanco et al., 2016). How stem cells decouple translation rate from cell cycle control has yet to be understood, and remains one of many intriguing questions in the stem cell field. 


\section{CONCLUDING REMARKS}

It has been more than five decades since the importance of translation control in early developmental processes was delineated through the study of the fertilization of sea urchin eggs (Hultin, 1961; Monroy et al., 1961; Tahmasebi et al., 2018b). However, the role of translational control in differentiation and maintenance of stem cells has been explored only recently. Technological advances in the studies of translation, combined

\section{REFERENCES}

Aviner, R., Geiger, T., and Elroy-Stein, O. (2013). Novel proteomic approach (PUNCH-P) reveals cell cycle-specific fluctuations in mRNA translation. Genes Dev. 27, 1834-1844. doi: 10.1101/gad.219105.113

Batista, P. J., Molinie, B., Wang, J., Qu, K., Zhang, J., Li, L., et al. (2014). m(6)A RNA modification controls cell fate transition in mammalian embryonic stem cells. Cell Stem Cell 15, 707-719. doi: 10.1016/j.stem.2014.09.019

Berlanga, J. J., Baass, A., and Sonenberg, N. (2006). Regulation of poly(A) binding protein function in translation: characterization of the Paip2 homolog, Paip2B. RNA 12, 1556-1568. doi: 10.1261/rna.106506

Blanco, S., Bandiera, R., Popis, M., Hussain, S., Lombard, P., Aleksic, J., et al. (2016). Stem cell function and stress response are controlled by protein synthesis. Nature 534, 335-340. doi: 10.1038/nature18282

Bulut-Karslioglu, A., Biechele, S., Jin, H., Macrae, T. A., Hejna, M., Gertsenstein, M., et al. (2016). Inhibition of mTOR induces a paused pluripotent state. Nature 540, 119-123. doi: 10.1038/nature20578

Bulut-Karslioglu, A., Macrae, T. A., Oses-Prieto, J. A., Covarrubias, S., Percharde, M., Ku, G., et al. (2018). The transcriptionally permissive chromatin state of embryonic stem cells is acutely tuned to translational output. Cell Stem Cell 22:e368. doi: 10.1016/j.stem.2018.02.004

Chen, T., Shen, L., Yu, J., Wan, H., Guo, A., Chen, J., et al. (2011). Rapamycin and other longevity-promoting compounds enhance the generation of mouse induced pluripotent stem cells. Aging Cell 10, 908-911. doi: 10.1111/j.14749726.2011.00722.x

Craig, A. W., Haghighat, A., Yu, A. T., and Sonenberg, N. (1998). Interaction of polyadenylate-binding protein with the eIF4G homologue PAIP enhances translation. Nature 392, 520-523. doi: 10.1038/33198

Delepine, M., Nicolino, M., Barrett, T., Golamaully, M., Lathrop, G. M., and Julier, C. (2000). EIF2AK3, encoding translation initiation factor 2-alpha kinase 3 , is mutated in patients with wolcott-rallison syndrome. Nat. Genet. 25, 406-409. doi: 10.1038/78085

Friend, K., Brooks, H. A., Propson, N. E., Thomson, J. A., and Kimble, J. (2015). Embryonic stem cell growth factors regulate eIF2alpha phosphorylation. PLoS One 10:e0139076. doi: 10.1371/journal.pone.0139076

Gage, F. H. (2000). Mammalian neural stem cells. Science 287, 1433-1438. doi: $10.1126 /$ science.287.5457.1433

Guzzi, N., Ciesla, M., Ngoc, P. C. T., Lang, S., Arora, S., Dimitriou, M., et al. (2018). Pseudouridylation of tRNA-derived fragments steers translational control in stem cells. Cell 173, 1204.e26-1216.e26. doi: 10.1016/j.cell.2018. 03.008

Gygi, S. P., Rochon, Y., Franza, B. R., and Aebersold, R. (1999). Correlation between protein and mRNA abundance in yeast. Mol. Cell Biol. 19, 1720-1730. doi: 10.1128/MCB.19.3.1720

Han, A. P., Yu, C., Lu, L., Fujiwara, Y., Browne, C., Chin, G., et al. (2001). Hemeregulated eIF2alpha kinase (HRI) is required for translational regulation and survival of erythroid precursors in iron deficiency. Embo J. 20, 6909-6918. doi: 10.1093/emboj/20.23.6909

Harding, H. P., Zeng, H., Zhang, Y., Jungries, R., Chung, P., Plesken, H., et al. (2001). Diabetes mellitus and exocrine pancreatic dysfunction in perk-/- mice reveals a role for translational control in secretory cell survival. Mol. Cell 7, 1153-1163. doi: 10.1016/S1097-2765(01)00264-7

Harding, H. P., Zhang, Y., Scheuner, D., Chen, J. J., Kaufman, R. J., and Ron, D. (2009). Ppp1r15 gene knockout reveals an essential role for translation initiation factor 2 alpha (eIF2alpha) dephosphorylation in mammalian with novel genetic approaches, are beginning to provide the essential tools required for understanding this critical step of gene expression in stem cell plasticity.

\section{AUTHOR CONTRIBUTIONS}

All authors contributed in conceptualizing and writing the review.

development. Proc. Natl. Acad. Sci. U.S.A. 106, 1832-1837. doi: 10.1073/pnas. 0809632106

Hartman, N. W., Lin, T. V., Zhang, L., Paquelet, G. E., Feliciano, D. M., and Bordey, A. (2013). mTORC1 targets the translational repressor 4E-BP2, but not S6 kinase 1/2, to regulate neural stem cell self-renewal in vivo. Cell Rep. 5, 433-444. doi: 10.1016/j.celrep.2013.09.017

He, J., Kang, L., Wu, T., Zhang, J., Wang, H., Gao, H., et al. (2012). An elaborate regulation of Mammalian target of rapamycin activity is required for somatic cell reprogramming induced by defined transcription factors. Stem Cells Dev. 21, 2630-2641. doi: 10.1089/scd.2012.0015

Henis-Korenblit, S., Shani, G., Sines, T., Marash, L., Shohat, G., and Kimchi, A. (2002). The caspase-cleaved DAP5 protein supports internal ribosome entry site-mediated translation of death proteins. Proc. Natl. Acad. Sci. U.S.A. 99, 5400-5405. doi: 10.1073/pnas.082102499

Hinnebusch, A. G., Ivanov, I. P., and Sonenberg, N. (2016). Translational control by $5^{\prime}$-untranslated regions of eukaryotic mRNAs. Science 352, 1413-1416. doi: 10.1126/science.aad9868

Hultin, T. (1961). Activation of ribosomes in sea urchin eggs in response to fertilization. Exp. Cell Res. 25, 405-417. doi: 10.1016/0014-4827(61)90290-7

Ingolia, N. T., Lareau, L. F., and Weissman, J. S. (2011). Ribosome profiling of mouse embryonic stem cells reveals the complexity and dynamics of mammalian proteomes. Cell 147, 789-802. doi: 10.1016/j.cell.2011.10.002

Ivanov, P., Emara, M. M., Villen, J., Gygi, S. P., and Anderson, P. (2011). Angiogenin-induced tRNA fragments inhibit translation initiation. Mol. Cell 43, 613-623. doi: 10.1016/j.molcel.2011.06.022

Ivanova, N. B., Dimos, J. T., Schaniel, C., Hackney, J. A., Moore, K. A., and Lemischka, I. R. (2002). A stem cell molecular signature. Science 298, 601-604. doi: 10.1126/science.1073823

Jovanovic, M., Rooney, M. S., Mertins, P., Przybylski, D., Chevrier, N., Satija, R., et al. (2015). Immunogenetics. Dynamic profiling of the protein life cycle in response to pathogens. Science 347:1259038. doi: 10.1126/science.1259038

Karim, M. M., Svitkin, Y. V., Kahvejian, A., De Crescenzo, G., Costa-Mattioli, M., and Sonenberg, N. (2006). A mechanism of translational repression by competition of Paip2 with eIF4G for poly(A) binding protein (PABP) binding. Proc. Natl. Acad. Sci. U.S.A. 103, 9494-9499. doi: 10.1073/pnas.06037 01103

Khajuria, R. K., Munschauer, M., Ulirsch, J. C., Fiorini, C., Ludwig, L. S., McFarland, S. K., et al. (2018). Ribosome levels selectively regulate translation and lineage commitment in human hematopoiesis. Cell 173, 90.e19-103.e19. doi: 10.1016/j.cell.2018.02.036

Khaleghpour, K., Svitkin, Y. V., Craig, A. W., DeMaria, C. T., Deo, R. C., Burley, S. K., et al. (2001). Translational repression by a novel partner of human poly(A) binding protein, Paip2. Mol. Cell 7, 205-216. doi: 10.1016/S1097-2765(01) 00168-X

Khan, Z., Ford, M. J., Cusanovich, D. A., Mitrano, A., Pritchard, J. K., and Gilad, Y. (2013). Primate transcript and protein expression levels evolve under compensatory selection pressures. Science 342, 1100-1104. doi: 10.1126/science. 1242379

Kleene, K. C. (1989). Poly(A) shortening accompanies the activation of translation of five mRNAs during spermiogenesis in the mouse. Development 106, 367-373.

Kristensen, A. R., Gsponer, J., and Foster, L. J. (2013). Protein synthesis rate is the predominant regulator of protein expression during differentiation. Mol. Syst. Biol. 9:689. doi: 10.1038/msb.2013.47

Le Bouteiller, M., Souilhol, C., Beck-Cormier, S., Stedman, A., BurlenDefranoux, O., Vandormael-Pournin, S., et al. (2013). Notchless-dependent 
ribosome synthesis is required for the maintenance of adult hematopoietic stem cells. J. Exp. Med. 210, 2351-2369. doi: 10.1084/jem.20122019

Lee, M. T., Bonneau, A. R., Takacs, C. M., Bazzini, A. A., DiVito, K. R., Fleming, E. S., et al. (2013). Nanog, Pou5f1 and SoxB1 activate zygotic gene expression during the maternal-to-zygotic transition. Nature 503, 360-364. doi: 10.1038/ nature12632

Li, J. J., Bickel, P. J., and Biggin, M. D. (2014). System wide analyses have underestimated protein abundances and the importance of transcription in mammals. PeerJ 2:e270. doi: 10.7717/peerj.270

Li, J. J., and Biggin, M. D. (2015). Gene expression. Statistics requantitates the central dogma. Science 347, 1066-1067. doi: 10.1126/science.aaa8332

Liberman, N., Gandin, V., Svitkin, Y. V., David, M., Virgili, G., Jaramillo, M., et al. (2015). DAP5 associates with eIF2beta and eIF4AI to promote internal ribosome entry site driven translation. Nucleic Acids Res. 43, 3764-3775. doi: 10.1093/nar/gkv205

Liu, Y., Beyer, A., and Aebersold, R. (2016). On the dependency of cellular protein levels on mRNA abundance. Cell 165, 535-550. doi: 10.1016/j.cell.2016. 03.014

Llorens-Bobadilla, E., Zhao, S., Baser, A., Saiz-Castro, G., Zwadlo, K., and MartinVillalba, A. (2015). Single-cell transcriptomics reveals a population of dormant neural stem cells that become activated upon brain injury. Cell Stem Cell 17, 329-340. doi: 10.1016/j.stem.2015.07.002

Lu, R., Markowetz, F., Unwin, R. D., Leek, J. T., Airoldi, E. M., MacArthur, B. D., et al. (2009). Systems-level dynamic analyses of fate change in murine embryonic stem cells. Nature 462, 358-362. doi: 10.1038/nature08575

Maier, T., Guell, M., and Serrano, L. (2009). Correlation of mRNA and protein in complex biological samples. FEBS Lett. 583, 3966-3973. doi: 10.1016/j.febslet. 2009.10.036

Meehan, T. F., Conte, N., West, D. B., Jacobsen, J. O., Mason, J., Warren, J., et al. (2017). Disease model discovery from 3,328 gene knockouts by the international mouse phenotyping consortium. Nat. Genet. 49, 1231-1238. doi: 10.1038/ng. 3901

Merrick, W. C., and Pavitt, G. D. (2018). Protein synthesis initiation in eukaryotic cells. Cold Spring Harb. Perspect. Biol. 10:a033092. doi: 10.1101/cshperspect. a033092

Mills, E. W., and Green, R. (2017). Ribosomopathies: there's strength in numbers. Science 358:eaan2755. doi: 10.1126/science.aan2755

Monroy, A., Vittorelli, M. L., and Guarneri, R. (1961). Investigations on the proteins of the cell fluid during the early development of the sea urchin. Acta Embryol. 4, 77-95.

Morita, M., Ler, L. W., Fabian, M. R., Siddiqui, N., Mullin, M., Henderson, V. C., et al. (2012). A novel 4EHP-GIGYF2 translational repressor complex is essential for mammalian development. Mol. Cell Biol. 32, 3585-3593. doi: 10.1128/MCB. 00455- 12

Paolini, N. A., Moore, K. S., di Summa, F. M., Fokkema, I. F. A. C., t Hoen, P. A. C., and von Lindern, M. (2018). Ribosome profiling uncovers selective mRNA translation associated with eIF2 phosphorylation in erythroid progenitors. PLoS One 13:e0193790. doi: 10.1371/journal.pone.0193790

Ramalho-Santos, M., Yoon, S., Matsuzaki, Y., Mulligan, R. C., and Melton, D. A. (2002). "Stemness": transcriptional profiling of embryonic and adult stem cells. Science 298, 597-600. doi: 10.1126/science.1072530

Rodgers, J. T., King, K. Y., Brett, J. O., Cromie, M. J., Charville, G. W., Maguire, K. K., et al. (2014). mTORC1 controls the adaptive transition of quiescent stem cells from G0 to G(Alert). Nature 510, 393-396. doi: 10.1038/nature 13255

Sadato, D., Ono, T., Gotoh-Saito, S., Kajiwara, N., Nomura, N., Ukaji, M., et al. (2018). Eukaryotic translation initiation factor 3 (eIF3) subunit e is essential for embryonic development and cell proliferation. FEBS Open Bio 8, 1188-1201. doi: 10.1002/2211-5463.12482

Sampath, P., Pritchard, D. K., Pabon, L., Reinecke, H., Schwartz, S. M., Morris, D. R., et al. (2008). A hierarchical network controls protein translation during murine embryonic stem cell self-renewal and differentiation. Cell Stem Cell 2, 448-460. doi: 10.1016/j.stem.2008.03.013

Sanchez, C. G., Teixeira, F. K., Czech, B., Preall, J. B., Zamparini, A. L., Seifert, J. R., et al. (2016). Regulation of ribosome biogenesis and protein synthesis controls germline stem cell differentiation. Cell Stem Cell 18, 276-290. doi: $10.1016 /$ j.stem.2015.11.004
Scheuner, D., Song, B., McEwen, E., Liu, C., Laybutt, R., Gillespie, P., et al. (2001). Translational control is required for the unfolded protein response and in vivo glucose homeostasis. Mol. Cell 7, 1165-1176. doi: 10.1016/S1097-2765(01) 00265-9

Schwanhausser, B., Busse, D., Li, N., Dittmar, G., Schuchhardt, J., Wolf, J., et al. (2011). Global quantification of mammalian gene expression control. Nature 473, 337-342. doi: 10.1038/nature10098

Sharma, K., Schmitt, S., Bergner, C. G., Tyanova, S., Kannaiyan, N., ManriqueHoyos, N., et al. (2015). Cell type- and brain region-resolved mouse brain proteome. Nat. Neurosci. 18, 1819-1831. doi: 10.1038/nn.4160

Shi, Z., Fujii, K., Kovary, K. M., Genuth, N. R., Rost, H. L., Teruel, M. N., et al. (2017). Heterogeneous ribosomes preferentially translate distinct subpools of mRNAs genome-wide. Mol. Cell 67, 71.e7-83.e7. doi: 10.1016/j.molcel.2017. 05.021

Signer, R. A., Magee, J. A., Salic, A., and Morrison, S. J. (2014). Haematopoietic stem cells require a highly regulated protein synthesis rate. Nature 509, 49-54. doi: 10.1038/nature13035

Signer, R. A., Qi, L., Zhao, Z., Thompson, D., Sigova, A. A., Fan, Z. P., et al. (2016). The rate of protein synthesis in hematopoietic stem cells is limited partly by 4E-BPs. Genes Dev. 30, 1698-1703. doi: 10.1101/gad.282756.116

Singh, A. M., and Dalton, S. (2009). The cell cycle and Myc intersect with mechanisms that regulate pluripotency and reprogramming. Cell Stem Cell 5, 141-149. doi: 10.1016/j.stem.2009.07.003

Sobala, A., and Hutvagner, G. (2013). Small RNAs derived from the $5^{\prime}$ end of tRNA can inhibit protein translation in human cells. RNA Biol. 10, 553-563. doi: $10.4161 /$ rna.24285

Sonenberg, N., and Hinnebusch, A. G. (2009). Regulation of translation initiation in eukaryotes: mechanisms and biological targets. Cell 136, 731-745. doi: 10. 1016/j.cell.2009.01.042

Spriggs, K. A., Bushell, M., and Willis, A. E. (2010). Translational regulation of gene expression during conditions of cell stress. Mol. Cell 40, 228-237. doi: 10.1016/j.molcel.2010.09.028

Sugiyama, H., Takahashi, K., Yamamoto, T., Iwasaki, M., Narita, M., Nakamura, M., et al. (2017). Natl promotes translation of specific proteins that induce differentiation of mouse embryonic stem cells. Proc. Natl. Acad. Sci. U.S.A. 114, 340-345. doi: 10.1073/pnas.1617234114

Tahmasebi, S., Alain, T., Rajasekhar, V. K., Zhang, J. P., Prager-Khoutorsky, M., Khoutorsky, A., et al. (2014). Multifaceted regulation of somatic cell reprogramming by mRNA translational control. Cell Stem Cell 14, 606-616. doi: 10.1016/j.stem.2014.02.005

Tahmasebi, S., Jafarnejad, S. M., Tam, I. S., Gonatopoulos-Pournatzis, T., MattaCamacho, E., Tsukumo, Y., et al. (2016). Control of embryonic stem cell selfrenewal and differentiation via coordinated alternative splicing and translation of YY2. Proc. Natl. Acad. Sci. U.S.A. 113, 12360-12367. doi: 10.1073/pnas. 1615540113

Tahmasebi, S., Khoutorsky, A., Mathews, M. B., and Sonenberg, N. (2018a). Translation deregulation in human disease. Nat. Rev. Mol. Cell Biol. 19, 791807. doi: 10.1038/s41580-018-0034- $\mathrm{x}$

Tahmasebi, S., Sonenberg, N., Hershey, J. W. B., and Mathews, M. B. (2018b). Protein synthesis and translational control: a historical perspective. Cold Spring Harb. Perspect. Biol. 10:a035584. doi: 10.1101/cshperspect.a035584

Truitt, M. L., Conn, C. S., Shi, Z., Pang, X., Tokuyasu, T., Coady, A. M., et al. (2015). Differential requirements for eIF4E dose in normal development and cancer. Cell 162, 59-71. doi: 10.1016/j.cell.2015.05.049

van Galen, P., Kreso, A., Mbong, N., Kent, D. G., Fitzmaurice, T., Chambers, J. E., et al. (2014). The unfolded protein response governs integrity of the haematopoietic stem-cell pool during stress. Nature 510, 268-272. doi: 10.1038/ nature 13228

Vogel, C., Abreu Rde, S., Ko, D., Le, S. Y., Shapiro, B. A., Burns, S. C., et al. (2010). Sequence signatures and mRNA concentration can explain two-thirds of protein abundance variation in a human cell line. Mol. Syst. Biol. 6:400. doi: $10.1038 / \mathrm{msb} .2010 .59$

Xue, S., and Barna, M. (2012). Specialized ribosomes: a new frontier in gene regulation and organismal biology. Nat. Rev. Mol. Cell Biol. 13, 355-369. doi: $10.1038 / \mathrm{nrm} 3359$

Yamanaka, S., Zhang, X. Y., Maeda, M., Miura, K., Wang, S., Farese, R. V., et al. (2000). Essential role of NAT1/p97/DAP5 in embryonic differentiation and 
the retinoic acid pathway. Embo J. 19, 5533-5541. doi: 10.1093/emboj/19. 20.5533

Yanagiya, A., Delbes, G., Svitkin, Y. V., Robaire, B., and Sonenberg, N. (2010). The poly(A)-binding protein partner Paip2a controls translation during late spermiogenesis in mice. J. Clin. Invest. 120, 3389-3400. doi: 10.1172/JCI43350

Yoffe, Y., David, M., Kalaora, R., Povodovski, L., Friedlander, G., Feldmesser, E., et al. (2016). Cap-independent translation by DAP5 controls cell fate decisions in human embryonic stem cells. Genes Dev. 30, 1991-2004. doi: 10.1101/gad. 285239.116

Zeng, L., Wan, Y., Li, D., Wu, J., Shao, M., Chen, J., et al. (2013). The m subunit of murine translation initiation factor eIF3 maintains the integrity of the eIF3 complex and is required for embryonic development, homeostasis, and organ size control. J. Biol. Chem. 288, 30087-30093. doi: 10.1074/jbc.M113. 506147

Zhang, Q., Shalaby, N. A., and Buszczak, M. (2014). Changes in rRNA transcription influence proliferation and cell fate within a stem cell lineage. Science 343, 298-301. doi: 10.1126/science. 1246384

Zhang, W., Feng, D., Li, Y., Iida, K., McGrath, B., and Cavener, D. R. (2006). PERK EIF2AK3 control of pancreatic beta cell differentiation and proliferation is required for postnatal glucose homeostasis. Cell Metab. 4, 491-497. doi: 10.1016/j.cmet.2006.11.002

Zismanov, V., Chichkov, V., Colangelo, V., Jamet, S., Wang, S., Syme, A., et al. (2016). Phosphorylation of eIF2alpha is a translational control mechanism regulating muscle stem cell quiescence and self-renewal. Cell Stem Cell 18, 79-90. doi: 10.1016/j.stem.2015. 09.020

Conflict of Interest Statement: The authors declare that the research was conducted in the absence of any commercial or financial relationships that could be construed as a potential conflict of interest.

Copyright $\odot 2019$ Tahmasebi, Amiri and Sonenberg. This is an open-access article distributed under the terms of the Creative Commons Attribution License (CC BY). The use, distribution or reproduction in other forums is permitted, provided the original author(s) and the copyright owner(s) are credited and that the original publication in this journal is cited, in accordance with accepted academic practice. No use, distribution or reproduction is permitted which does not comply with these terms. 